\title{
Melderecht datenschutzkonform gestalten!
}

Das vom Deutschen Bundestag am 28. Juni 2012 beschlossene neue Melderecht weist erhebliche datenschutzrechtliche Defizite auf. Schon die im Regierungsentwurf enthaltenen Datenschutzbestimmungen blieben zum Teil hinter dem bereits geltenden Recht zurück. Darüber hinaus wurde der Regierungsentwurf durch das Ergebnis der Ausschussberatungen des Bundestages noch einmal deutlich verschlechtert.

Bei den Meldedaten handelt es sich um Pflichtangaben, die die Bürgerinnen und Bürger gegenüber dem Staat machen müssen. Dies verpflichtet zu besonderer Sorgfalt bei der Verwendung, insbesondere wenn die Daten an Dritte weitergegeben werden sollen.

Die Datenschutzbeauftragten des Bundes und der Länder fordern daher den Bundesrat auf, dem Gesetzentwurf nicht zuzustimmen, damit im Vermittlungsverfahren die erforderlichen datenschutzgerechten Verbesserungen erfolgen können. Dabei geht es nicht nur darum, die im Deutschen Bundestag vorgenommenen Verschlechterungen des Gesetzentwurfs der Bundesregierung rückgängig zu machen, vielmehr muss das Melderecht insgesamt datenschutzkonform ausgestaltet werden. Hierfür müssen auch die Punkte aufgegriffen werden, die von den Datenschutzbeauftragten im Gesetzgebungsverfahren gefordert worden sind, aber unberücksichtigt blieben.

Die Konferenz der Datenschutzbeauftragten des Bundes und der Länder hält insbesondere in den folgenden Punkten Korrekturen und Ergänzungen für erforderlich:

- Einfache Melderegisterauskünfte für Zwecke der Werbung und des Adresshandels bedürfen ausnahmslos der Einwilligung des Meldepflichtigen. Dies gilt auch für die Aktualisierung solcher Daten, über die die anfragenden Stellen bereits verfügen und die Weitergabe der Daten an Adressbuchverlage. Melderegisterauskünfte in besonderen Fällen, wie Auskünfte an Parteien zu Wahlwerbungszwecken und an Presse oder Rundfunk über Alters- und Ehejubiläen sollten im Interesse der Betroffenen ebenfalls nur mit Einwilligung der Meldepflichtigen zulässig sein.

- Der Meldepflichtige muss sonstigen einfachen Melderegisterauskünften widersprechen können. Die Übermittlung hat bei Vorliegen eines Widerspruchs zu unterbleiben, sofern der Anfragende kein rechtliches Interesse geltend machen kann.

- Die Zweckbindung der bei Melderegisterauskünften übermittelten Daten ist zu verstärken. Die im Gesetzentwurf nur für Zwecke der Werbung und des Adresshandels vorgesehene Zweckbindung muss auch auf die Verwendung für sonstige gewerbliche Zwecke erstreckt werden.

- Angesichts der Sensibilität der Daten, die im Rahmen einer erweiterten Melderegisterauskunft mitgeteilt werden, und der relativ niedrigen Voraussetzungen, die an die Glaubhaftmachung des berechtigten Interesses gestellt werden, sollte anstelle des berechtigten Interesses ein rechtliches Interesse an der Kenntnis der einzelnen Daten vom potentiellen Datenempfänger glaubhaft gemacht werden müssen.

- Die Erteilung einfacher Melderegisterauskünfte im Wege des Abrufs über das Internet oder des sonstigen automatisierten Datenabrufs sollte wie bisher nur zulässig sein, wenn die betroffene Person ihr nicht widerspricht.

- Die Hotelmeldepflicht sollte entfallen, weil es sich dabei um eine sachlich nicht zu rechtfertigende Vorratsdatenspeicherung handelt. Hotelgäste dürfen nicht schlechthin als Gefahrenquellen oder (potentielle) Straftäter angesehen und damit in ihrem Persönlichkeitsrecht verletzt werden.

- Die erst vor wenigen Jahren abgeschaffte Mitwirkungspflicht des Wohnungsgebers bei der Anmeldung des Mieters darf nicht wieder eingeführt werden. Die Verpflichtung des Meldepflichtigen, den Vermieter zu beteiligen, basiert auf einer Misstrauensvermutung gegenüber der Person des Meldepflichtigen. Der Gesetzgeber hat die damalige Abschaffung der Vermietermeldepflicht unter anderem damit begründet, dass die Erfahrungen der meldebehördlichen Praxis zeigen, dass die Zahl der Scheinmeldungen zu vernachlässigen ist. Es liegen keine Anhaltspunkte dafür vor, dass sich dies zwischenzeitlich geändert hat. Ferner steht der Aufwand hierfür - wie auch bei der Hotelmeldepflicht - außer Verhältnis zum Nutzen.

Die Stellungnahme der Konferenz der Datenschutzbeauftragten des Bundes und der Länder vom 22. August $2012 \mathrm{zu}$ dem vom Deutschen Bundestag am 28. Juni 2012 beschlossenen Gesetz zur Fortentwicklung des Meldewesens finden sie in diesem $\mathrm{Heft}^{1}$.

Konferenz der Datenschutzbeauftragten des Bundes und der Länder, Entschließung vom 22. August 2012

1 DuD, 2012, Heft 11, Dokumentation, S. 837 